\title{
Metanetli ve Sürdürülebilir Bir Gelecek için Tasarım, Sanat ve Oyun: Çocuklar ve Gençler için Atölye Çalışmaları
}

\author{
Aktan Acar \\ TOBB Ekonomi ve Teknoloji Üniversitesi \\ ORCID: 0000-0001-7243-3575 \\ Nalan Akduman \\ Abdurrahim Karakoç Illkokulu
}

\author{
A. Şebnem Soysal Acar \\ Gazi Üniversitesi, Tip Fakültesi \\ ORCID: 0000-0002-6263-2340 \\ Yildiray Lise \\ Doğa Koruma Merkezi Vakfı
}

Öz

Tasarım egzersizleri, yaratıcı drama ve sanatla terapi teknikleri kullanarak, iklim değişikliği ve buna bağlı olarak yaşanan ve yaşanacak olan değişiklikler üzerine çocuklara ve gençlere yönelik bilgilendirme ve farkındalık oluşturma; uyum ve işbirliği yetilerini güçlendirme; ve bu süreçlerin oluşturabileceği olumsuz duygudurumlarn ile baş edebilme becerisi kazandırma amaçları doğrultusunda ilki 2017 yılı ocak ayı, ikincisi ise 2018 yılı ocak ayında olmak üzere, farklı yaş gruplarına yönelik iki atölye çalışması yapılmıştır. Atölyeler, TOBB Ekonomi ve Teknoloji Üniversitesi Mimarlık Bölümü 1. Sınıf Temel Tasarım Stüdyosu öğrencileri ile Abdurrahim Karakoç İlkokulu öğrencilerinin katılımı ile TOBB Ekonomi ve Teknoloji Üniversitesi Teknoloji Merkezi Binası'nda yer alan Mimarlık Bölümü stüdyolarında gerçekleştirilmiştir. Bir yıl arayla yapılan bu iki çalışmanın farklı yaş, cinsiyet ve eğitim durumuna göre bireyler üzerinde farklılaşma yarattı̆̆ı görüldü. Değerlendirmeler sonucunda, atölyelerin tüm katıltmo ve yürütücüler için önemli bir deneyim, farkındalık, bilgi ve beceri kazanımı să̆ladığından hareketle, etkinliğin diğer ilköğretim okullarına yaygınlaştııılması için çalışma yapılması kararı alınmıştır.

Anahtar Kelimeler: İklim değişikliği, metanetli toplumlar, tasarım ve yaratıcı drama teknikleri. 


\title{
Design, Art and Game for a Resilient and Sustainable Future: Workshops for Children and Youth
}

\author{
Aktan Acar \\ TOBB ETU \\ ORCID: 0000-0001-7243-3575 \\ Nalan Akduman \\ Abdurrahim Karakoç Primary School
}

\author{
A. Şebnem Soysal Acar \\ Gazi University \\ ORCID: 0000-0002-6263-2340 \\ Yildiray Lise \\ The Nature Conservation Center
}

\begin{abstract}
This study presents the results of two climate change oriented workshops conducted with first year architecture students and primary school children. The objectives of the workshops were to help the participants to acquire knowledge and develop awareness, improve their adaptation and cooperation abilities, and enhance their cognitive skills to cope with depressive mood and anxiety in living and combating climate change by means of design exercises, creative drama and therapy techniques. Participants were first-year Basic Design Studio students from TOBB University of Economics and Technology (TOBB ETU) Department of Architecture and students from Abdurrahim Karakoç Elementary School. The workshops were conducted in the studios of TOBB ETU Department of Architecture in 2017 and 2018. It was concluded that activities raise an awareness and made a difference regarding to their age, sex, and education level. It was decided to disseminate the results and workshop activity to other elementary schools in Ankara.
\end{abstract}

Keywords: Climate change, resilient societies, design and creative drama techniques. 


\section{Giriş}

İklim değişikliğine bağlı tehdit her geçen gün büyümekte ve gözlemlenebilir etkileri çoğalmaktadır. Yaşanan olumsuz etkilerin ortaya çıkmasının engellenemeyeceği yönündeki görüşler ve veriler ağırlık kazanmaktadır. Buna bağlı olarak, son yıllarda, yıkıcı etkilerin azaltılması, olumlu sonuçların etki alan ve biçimlerinin arttırılması yönünde daha fazla politika geliştirilmektedir. Bu çabalara karşın, içinde bulunduğumuz İnsan Çağı'nın neden olduğu ve gelecekte neden olabileceği yıkımlardan geriye kalanların rehabilitasyonu adına daha iyi, dengeli, sürdürülebilir ve metin ekosistemler bütünü için insan varlığını yadsıma ya da yüceltme anlayışı da zayıflamaktadır. İnsan, doğanın sorumlu ve etkin bir aktörü olarak görülmektedir. Bu aktörün hem çevresi hem de bütün yaş, cinsel yönelim, yaşam biçimi, bilgi, beceri, yeterlilik grupları ile iletişim, etkileşim ve iş birliği içinde olması gerektiğini ileri süren bir perspektif öne çıkmaktadır. Bu doğrultuda, yerel, bölgesel ve uluslararası ölçekte bilgilendirme, farkındalık ve mücadele çalışmaları hız kazanmaktadır. Bu hassasiyetin nedeni küresel boyutta yaşanması beklenen değişimin olumsuz etkilerinden potansiyel olarak en çok zararı görecek olan çocukların ve gençlerin korunmasidır (Codreanu, Celenza ve Jacobs, 2014, s. 630-631; Datar, Liu, Linnemayr ve Stecher, 2013, s. 3; Midtbust, Dyregrov ve Djup, 2018, s. 13; UNICEF, 2016, s. 9-17). Koruma sadece gelecekte olabileceklere ilişkin senaryolara dair değildir. Mevcut bilginin aktarılış biçimi, dijital çağın getirdiği bilgi kirlenmesine karşın medya okur yazarlığının gelişmesi, yaşa uygun içeriklerin oluşturulması ve bireylerin bunlarla karşılaştırılmasının sağlanması da en önemli ihtiyaçların başında gelmektedir

1990-2000 yılları arasında yılda 66,5 milyon çocuğun doğal afetlerden etkilendiği bilinmektedir (UNICEF, 2012, s.5). Bu sayının yıl bazında 175 milyona çıkacağ Çocukların ailelerini veya kendilerine bakım veren kişileri kaybetmeleri, gündelik hayatlarının, en önemlisi eğitimlerinin kesintiye uğraması en ciddi risktir. Aşırı sıcak ve doğrudan güneş ışınlarına maruz kalmaya bağlı olarak, sıcak çarpması ve bitkinlik gibi olumsuzlukların yanı sıra vücut kimyasında bozukluklar ve hatta cilt tehlikesi de söz konusudur. Su yoluyla bulaşan hastalıklar ve ishal nedeniyle hastaneye yatırılan çocuk sayısı, 1sıdaki her $1{ }^{\circ} \mathrm{C}$ artışa bağlı olarak \%8 oranında artmaktadır (Checkley ve diğerleri, 2000, s.448). Çocukların, hava kirliliğinin kısa dönem ve uzun dönem etkilerine karşı erişkinlere göre daha duyarlı olduğu 
bilinmektedir (Shea, 2007, s.1359). İklim değişikliği ve hava kirliliği erken doğuma, düşük doğum ağırlığına ve bebek ölüm oranlarında artışa neden olmaktadır (Kim, 2004, s.1699). Sıcaklık değişiklikleri ile ilişkili olarak polenlerde ve havadaki diğer alerjen miktarındaki çoğalma ile birlikte çocuklarda astım ve solunum yolu enfeksiyonlarının sıklığı ve şiddetinde artış gözlenmektedir (Beggs ve Bambrick, 2005, s.915-916). Felaketler ve hastalıklar, travma sonrası çeşitli duygudurumu bozuklukları ve davranış sorunları riskini arttırmaktadır. Çocuklarda ve ergenlerde uyku bozukluğu, üzüntü/keder, saldırgan davranışlar, madde kullanımı veya bağımlılığında artış olduğu yönünde veriler mevcuttur (Ahern, Kovats, Wilkinson, Few ve Matthies, 2005, s.38-39).

Çocukların ve gençlerin duyarlılığı ve farkındalığı iklim değişikliğinin olumsuz etkileri ile mücadelenin en önemli ayağını oluşturmaktadır. Onlarsız hiçbir politika, strateji, önlem ya da eylemin ne bugün ne de gelecekte başarılı olamayacağı ortadadır. Bu doğrultuda, çocuklarda ve gençlerde bilgilendirme ve farkındalık oluşturma çalışmalarının, katılım, iş birliği ve uyum becerilerini arttırmaya yönelik eylemlerle birlikte düşünülmesinde büyük fayda olduğu söylenebilir.

Bu noktada, iş birliği ve uyum becerilerinin iki yüzü olduğunun altını çizmek gerekmektedir. İklim değişikliği ile mücadelede, yeryüzünün ve insanlığın diğer sorunlarında olduğu gibi, bireylerin alacakları sorumluluklar, yaş, gelişim, bilgi farkındalıklarına uygun biçimde olmalıdır. Bireysel farkındalıklar ve iş birliğine dayalı sorun çözme becerilerinin gelişimi de bu anlayışla dikkate alınmalı ve desteklenmelidir. Ancak yerküreyi bekleyen tehlike ile sağlıklı ve sürdürülebilir bir mücadele için uzmanlık gerektiren iş birlikleri ve sorun çözme stratejilerinin yanında bütün bu süreci fiziksel olarak atlatabilmek için sürdürülebilir psikolojik iyilik halinin gerekliliği de göz ardı edilmemelidir. Özellikle de dönüşümü bizzat yaşayacak olan çocuklar ve gençler için sürecin ayrıntılandırılması daha fazla önem kazanmaktadır.

Çocukların erişebildikleri ancak gelişim düzeylerine uygun biçimde süzülmemiş çevirim içi malumat ve özellikle sosyal medyada hâkim olan bilgi kirliliği önemli bir sorundur. İklim değişikliği konusunda edindikleri bilimsel bilgi ve kazandıkları farkındalığın, çocuklar ve gençlerin duygudurumu ve kaygı düzeylerine etkisi hakkında, özellikle ülkemizde, çok az çalışma bulunmaktadır. Bu anlamda, bilgilendirme ve/veya farkındalık çalışmalarının çocuklar ve gençlerin fiziksel, bilişsel ve duygusal hazır bu- 
lunuşluklarına ve gelişim seviyelerine uygun biçimde, kaygı düzeylerinde meydana gelecek değişiklikler dikkate alınarak, geliştirilmesi ve uygulanması büyük önem taşımaktadır.

Oyun, sanat ve tasarım yoluyla araştırma, farkındalık kazanma ve öğrenme süreçleri bu anlamda çok değerli olanaklar barındırmaktadır. Bu tür süreçler, bireylerin iş birliğine dayalı, yaratıcı sorun çözme becerilerini geliştirirken ilgili alanda ortaya çıkmış ya da çıkması muhtemel kaygı ve korkulara yönelik bir destek noktası oluşturma fırsatı yaratmaktadır. Çocuklar ve gençler için oyun, yaratıcı drama ve tasarım etkinlikleri, yukarıda bahsedilen uyum ve psikolojik iyilik hali için başvurulabilecek güçlü bir araç olarak öne çıkmaktadır. Yaşıt ya da benzer özellikler taşıyan gruplar arası etkinlikler oldukça yaygındır. Ancak farklı yaş grupları arasında iletişim, iş birliği ve etkileşime dayalı çalışmalara, fiziksel imkân ve koşullar başta olmak üzere, birçok nedenden dolayı aynı sıklıkta rastlanılmamaktadır. Bu tür çalışmalarda yaş gruplarının farklılığını dezavantajdan avantaja dönüştürmek için birçok alandan uzmanın iş birliği yapması ve uygun fiziksel koşulların sağlanması büyük önem taşımaktadır.

Bu çalışmanın yazarları, yukarıda aktarılan veriler, kaygılar ve düşüncelerden hareketle, tasarım egzersizleri, yaratıcı drama ve sanatla terapi teknikleri kullanarak

- İklim değişikliği ve buna bağlı olarak yaşanan ve yaşanacak olan değişiklikler üzerine çocuklara ve gençlere yönelik bilgilendirme ve farkındalik oluşturma

- Uyum ve işbirliği becerileri kazandırma

- Bu süreçlerin oluşturabileceği olumsuz duygudurumları ile baş edebilme becerisi edindirme amaçları doğrultusunda bir araya gelmişlerdir.

Yazarlar, ilki 2017 yılı ocak ayı, ikincisi ise 2018 yılı ocak ayında, çocuklar ve gençler için olmak üzere iki farklı yaş grubuna yönelik iki atölye çalışması yapmışlardır. Atölyeler, TOBB Ekonomi ve Teknoloji Üniversitesi (TOBB ETÜ) Mimarlık Bölümü 1. Sınıf Temel Tasarım Stüdyosu öğrencileri ve Abdurrahim Karakoç İlköğretim okulu öğrencilerinin katılımı ile TOBB ETÜ Mimarlık Bölümü stüdyolarında gerçekleştirilmiştir. 


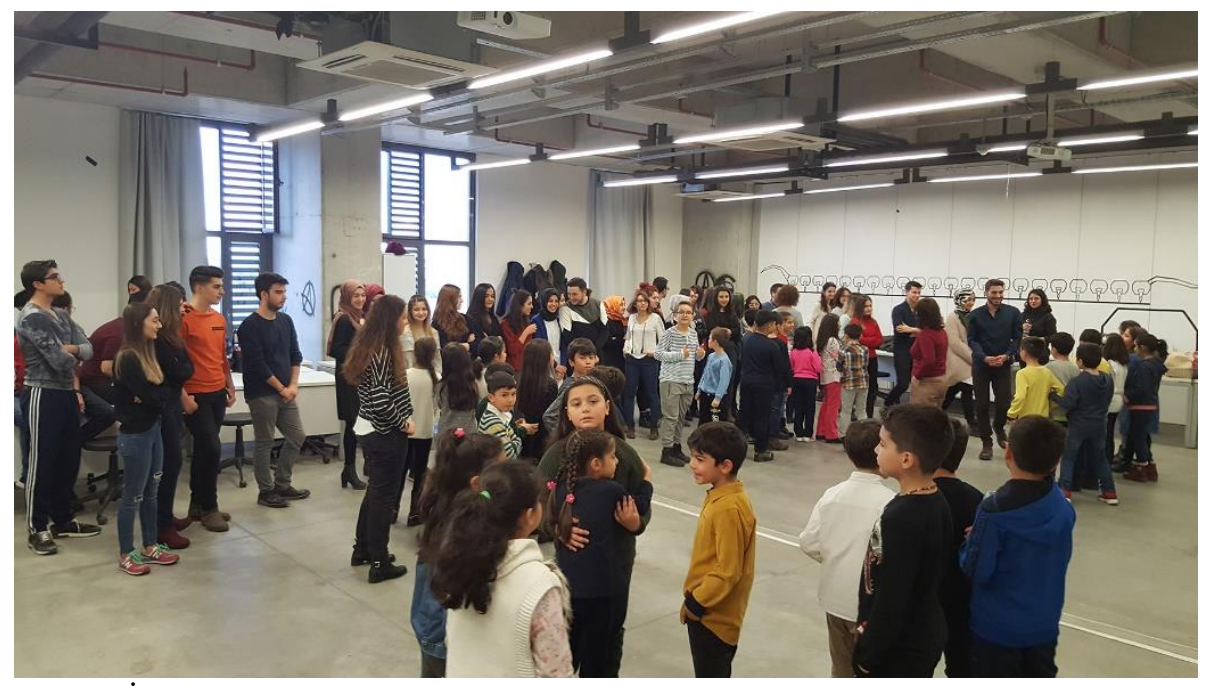

Şekil 1. İlköğretim öğrencileri ile mimarlık öğrencilerinin tanışma ve ısınma anları.

\section{Uygulama}

Çalışmaya, Mimarlık Bölümü Temel Tasarım Stüdyosuna kayıtlı ve katılım için gönüllü olan 38 mimarlık öğrencisi ile 2017 yılında 2. sınıfa, 2018 yılında ise 3. sınıfa kayıtlı olan aynı 38 ilköğretim okulu öğrencisi katılmıştır. Atölye çalışması bilgilendirme ve kaygılara yönelik söyleşi, ısınma ve tanışma oyunları ile bir mimarlık öğrencisi ve bir ilköğretim öğrencisinden oluşan ekiplerin tasarla-yap etkinliğinden oluşmuş ve toplamda 4 saat sürmüştür.

İlk olarak uzman biyolog Yıldıray Lise tarafından ekosistemler, iklim değişimi ve yerküre yaşanacak değişimler hakkında bir sunum yapıldı. Yerküre üzerinde yaşanacak hem olumlu hem de olumsuz değişimlerden bahsedilmesine rağmen, beklenildiği üzere, öğrencilerin felaketler, kaybedilecekler ve en çok da bir daha erişemeyeceklerini düşündükleri besinler ve özellikle de meyveler konusunda kaygılandıkları gözlendi. Çocuklar düşünceleri ve kaygılarını ifade ettikten sonra çocuk psikoloğu Prof. Dr. A. Şebnem Soysal Acar tarafından, ifade edilen kaygılardan yola çıkan ve çalışmanın amacı ve yöntemini açıklayan bir sunum yapıldı ve çocukların soruları yanitland1. 


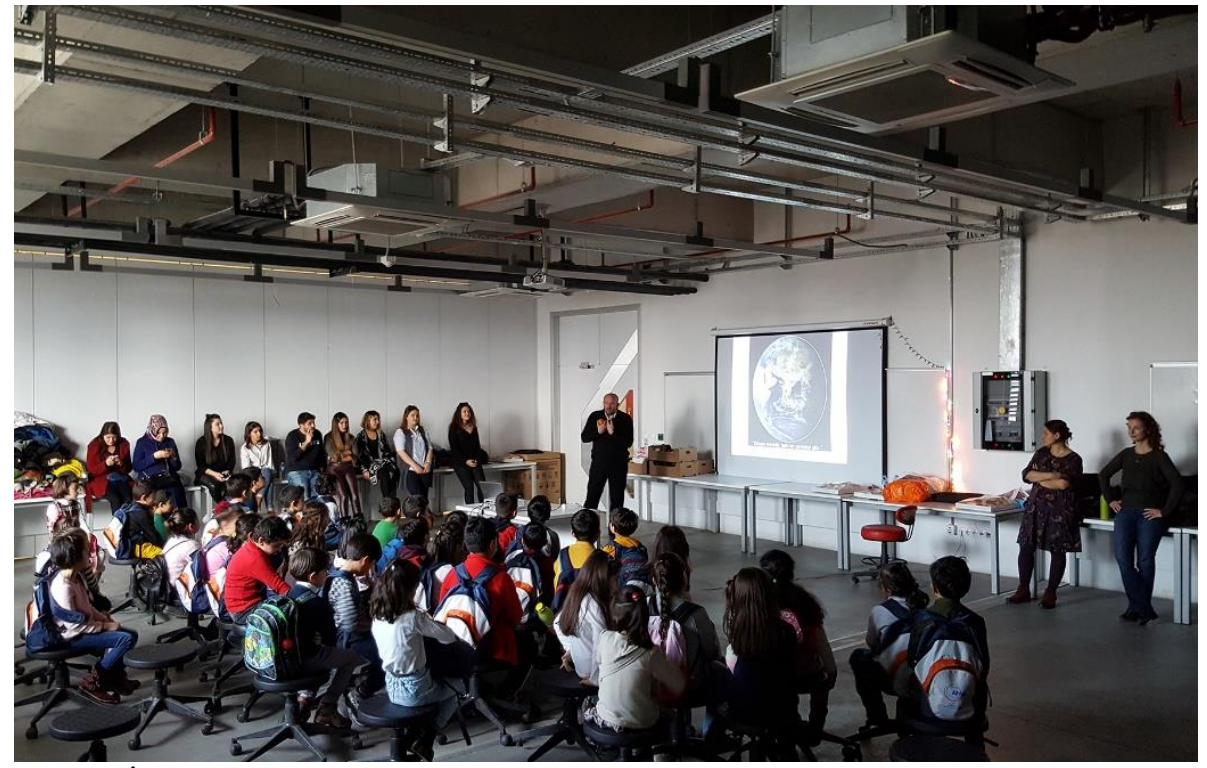

Şekil 2. İklim değişikliği ve ekosistemler hakkında bilgi veriliyor.

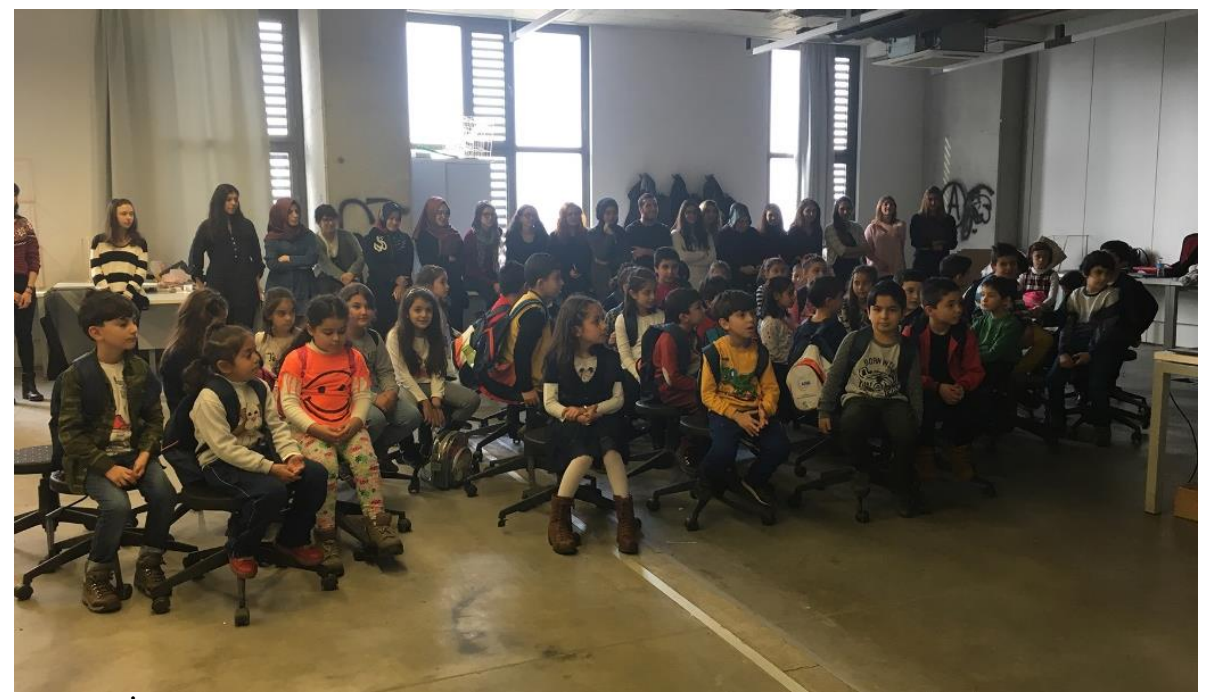

Şekil 3. İklim değişikliği ve ekosistemler hakkında bilgi veriliyor.

Daha sonra iki yaş grubunun öncelikle kaygı düzeylerinin azalması, tanışması, kaynaşması ve sürece ısınması için oyunlar oynandı. Sınıf öğretmeni ve aynı zamanda yaratıcı drama eğitmeni ve sanat terapisti olan Nalan Akdu- 
man'ın çocuk oyunları ve yaratıcı drama etkinliklerinden uyarladığı oyunlardan ilk yıl "Eriyen Buz Dağları" ile "Susuz Göl ile Kurbağalar", ikinci yıl ise "Hızlı Gonzales" ile "Algo" isimli oyunlar oynatıldı.

"Eriyen Buz Dağları" oyununda katılımcıların karşılıklı yüz yüze bakacak şekilde sıra olmaları sağlandı. İkişer kişilik gruplar oluşturmak için birer eş seçmeleri istendi. Etkinlik alanına gazete kâğıtları serildi ve çiftlere gazete kâğıtlarının üzerine çımaları söylendi. "Kutup ayısı aileleri, buz dağlarının üzerinde yaşıyor. İklim değişikliği sebebi ile buz dağları eriyor ve yok oluyor. Müzik çaldığında buz dağları erimeye başlayacak, ayı aileleri suya atlayıp, yüzecekler. Müzik durduğunda her aile buz dağının üzerine çıkmaya uğraşacak. Yer bulamayan ayılar, oyundan elenecekler" yönergesi verildi. Oyun ilerledikçe kâğıtlar azaltıldı. Azalan kâğıtlar üzerinde kalabalık aile grupları oluştu. Kâğıda sığamayan aileler ve kâğıtlar gittikçe azaltılarak oyuncular elendi. Oyunun sonunda katılımcıların evini kaybetmek, kalabalık arasında kalmak gibi yaşantılara dair paylaşımları alındı.

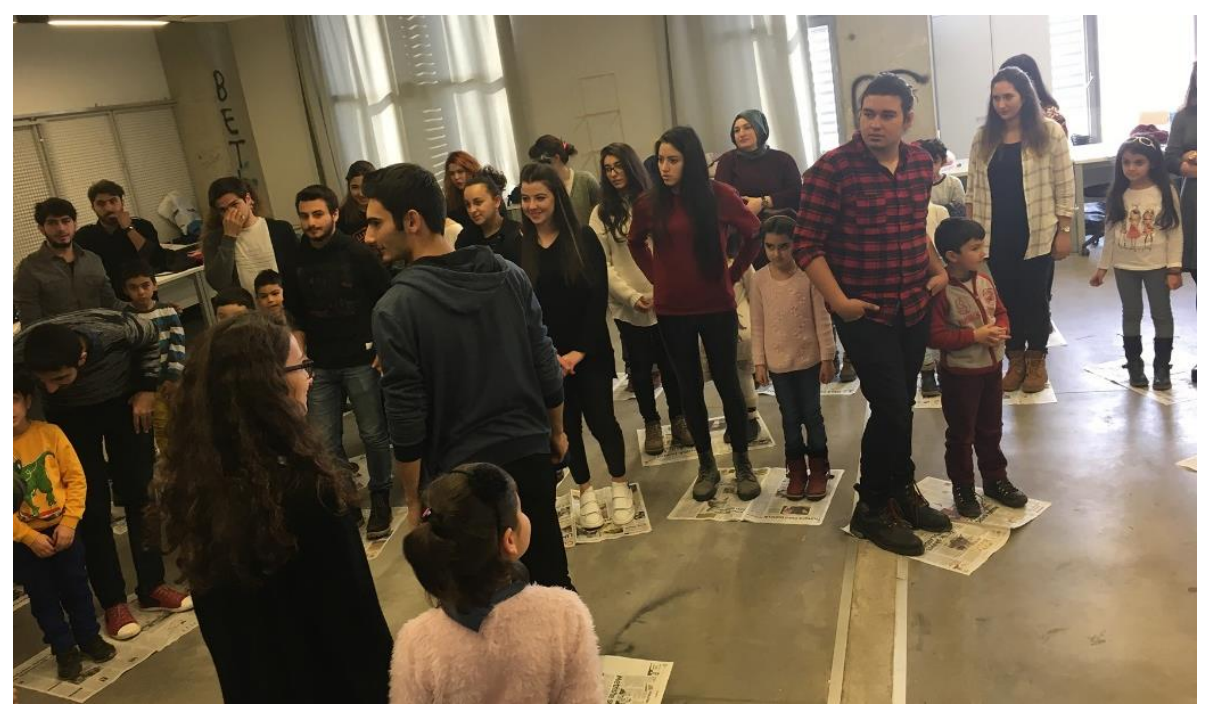

Şekil 4. Eriyen Buz Dağları oyunu.

İkinci olarak oynanan "Susuz Göl ve Kurbağalar" oyununda oyuncular iki gruba ayrıldı. Katılımcılar ilk oyundaki eşleri ile birlikte gruplara dağıldılar. Ard arda dizilecek şekilde iki grup yan yana salona yerleşti. Her grubun karşısına kurbağa olmayı kabul eden öğrenciler yerleştirildi. En arkada bulunan öğrencilere dört adet kova verildi. Oyun düzeninin kurulmasının ardından "Küresel iklim değişiklikleri yüzünden iki göl kurumak üzere. Göldeki 
kurbağaların yaşayabilmesi için suya ihtiyacı var. Halkın da kurbağalara... Çünkü kurbağalar hastalık yapan sinekleri yiyerek besleniyor. Bu sebeple gölünü en hızlı şekilde dolduran köy halkı, kurbağalarını yaşatıp, oyunu kazanacak." yönergesi verildi. Üç defa, kurallara uygun biçimde baş üstünde taşıyarak, kovaları önden arkaya en hızlı ulaştıran grup oyunu kazandı. Kurbağalara ve köy halkına duyguları ve düşünceleri soruldu. Paylaşımlar dinlendi.

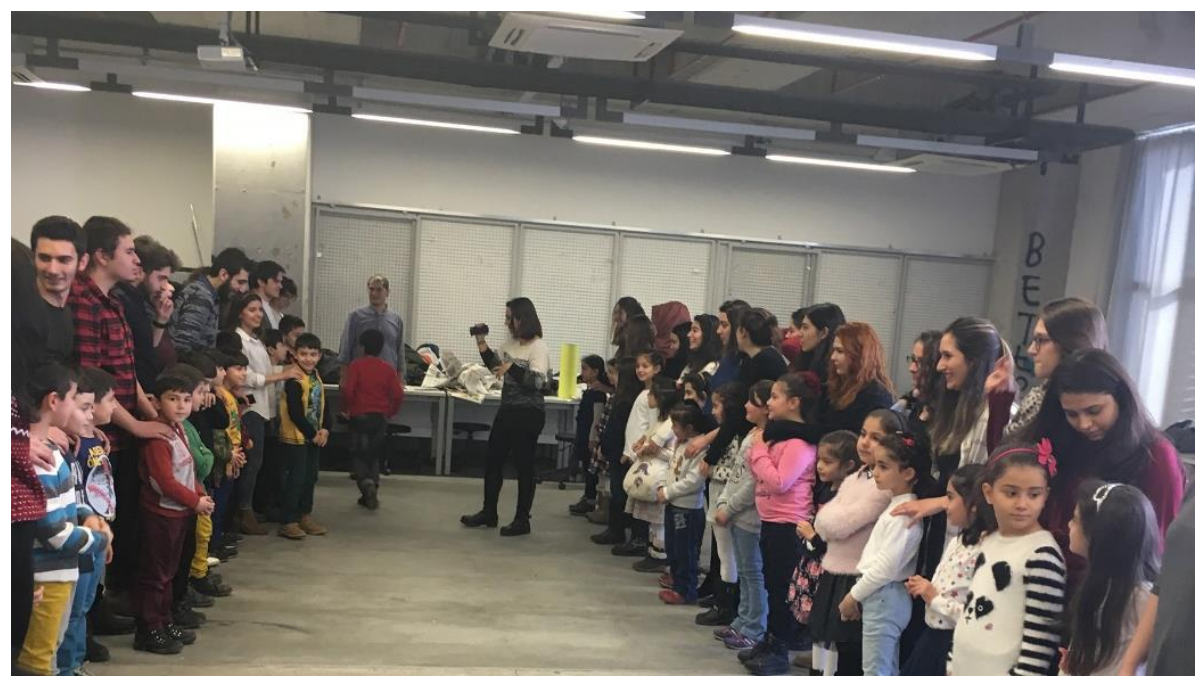

Şekil 5. Susuz Göl ve Kurbağalar oyunu.

"Hızlı Gonzales" oyununda salondaki katılımcılar karşılıklı 2 grup olacak şekilde 4 gruba ayrıldı. Her grupta farklı yaş gruplarından eşit sayıda katılımcı olmasına dikkat edildi. Her grubun başına bir gözetmen yerleştirildi. Ortadaki gözetmen gruptaki her katılımcıyı temsil eden 1 ile 9 arasındaki sayıları istediği sıklık ve tekrarda 12 kez yüksek sesle bağırarak duyurmakla sorumlu tutuldu. Oyunculara ekosistem çalışmasında kullanacakları 9 adet sözcük, her birinde sadece biri olacak şekilde, dağıtıldı. Karşılıklı eşlerin aynı sözcükleri alması sağlandı. Oyun başlamadan önce karşılıklı gruplar sırt sırta döndü. Kurala göre gözetmenin söylediği sayı ile belirlenen oyunculardan en hızlı dönen ve elindeki sözcüğü rakibinden önce söyleyen oyuncunun takımına puan kazandıracağı ifade edildi. İlk turda kazanan gruplar arasında bir karşılaşma daha yapıldı. Oyun sonunda kartlardaki sözcükler üzerine düşünceler paylaşıldı.

"Algo Oyunu"nda ise oyuncular 18 kişilik dört gruba ayrıld1. Her grupta bir yetişkin ile bir küçük öğrenci eşleştiler. On gönüllü katılımcıya takımların 
renklerini temsil eden içlerinde her takımın kendi ekosistemine ait fotoğraflar, notlar, açıklamalar içeren kâğıtlar bulunan iki adet zarf verildi. İki gruptan birer çift oyun alanına geldi. Büyük katılımcının gözü bağlandı. Gözü açık olan ilkokul öğrencisi eşin verdiği "başla" komutu ile gözü bağlı olan erişkin katılımcı hareket etmeye başladı ve eşinin yönlendirmeleri ile (sağa, sola, yana, arkaya, ilerle, dur, vb.) zarfa ulaşmaya çalıştı. Zarfı teslim eden gönüllü "bitti" diye seslendi. Bu komutu alan katılımc göz bandını açtı, hızla oyun alanını terk etti. Takımın diğer çifti aynı kurallar ile oyun alanına girdi. Zarflarını ilk toplayan ekip oyunu kazandı. Etkinlik diğer iki grubun yarışması tamamlanana kadar devam etti. Oyunun ardından salona yerleştirilmiş olan kartonlara oyun ve ekosistem çağrışımları içeren sözcükler yazıldı. Kartonlara yazılan çağrışımlar, ekosistemlere uyum ve sürdürülebilirlik için insanın etkisi, yeterliliklerimiz ve zayıf yönlerimiz bağlamında tartışıldı. Başkalarının bize etkisi, birlikte çalışma, yönlendirme, değişim için hızlı olmak ve karar vermek konularının katılımcılar tarafından değerlendirilmesi istendi.

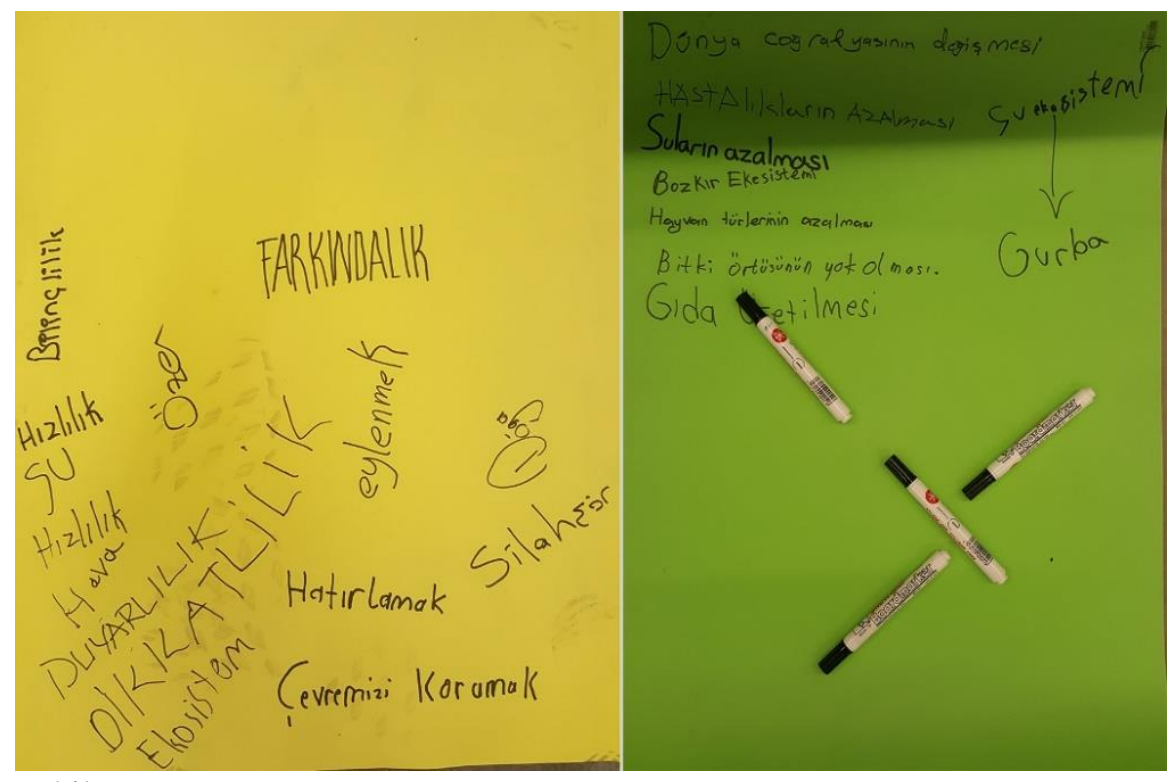

Şekil 6. Algo Oyunu Kartonları.

2017 yılında yapılan atölyede oyunlardan sonra farklı yaş grupları arasında oluşturulan ikili takımlar masalara yerleştirildiler. Takımlardan, yaşam alanı iklim değiş̧ikliğinden etkilenecek canlı ya da cansız bir yerküre sakini ve yer belirlemeleri, belirledikleri aktörler için yeni bir yuva tasar- 
lamaları istendi. Katılımcılar, verilen 2 saatlik süreyi fikir üreterek, fikirlerini tartışıp test ederek, maket, çizi, boya aracılığ 1 ile hayata geçirmek için kullandılar. 2018 yılında ise bir insan, bir hayvan, bir bitki ve bir tane de cansız varlık için yeni bir yaşam alanı tasarlamaları istendi.

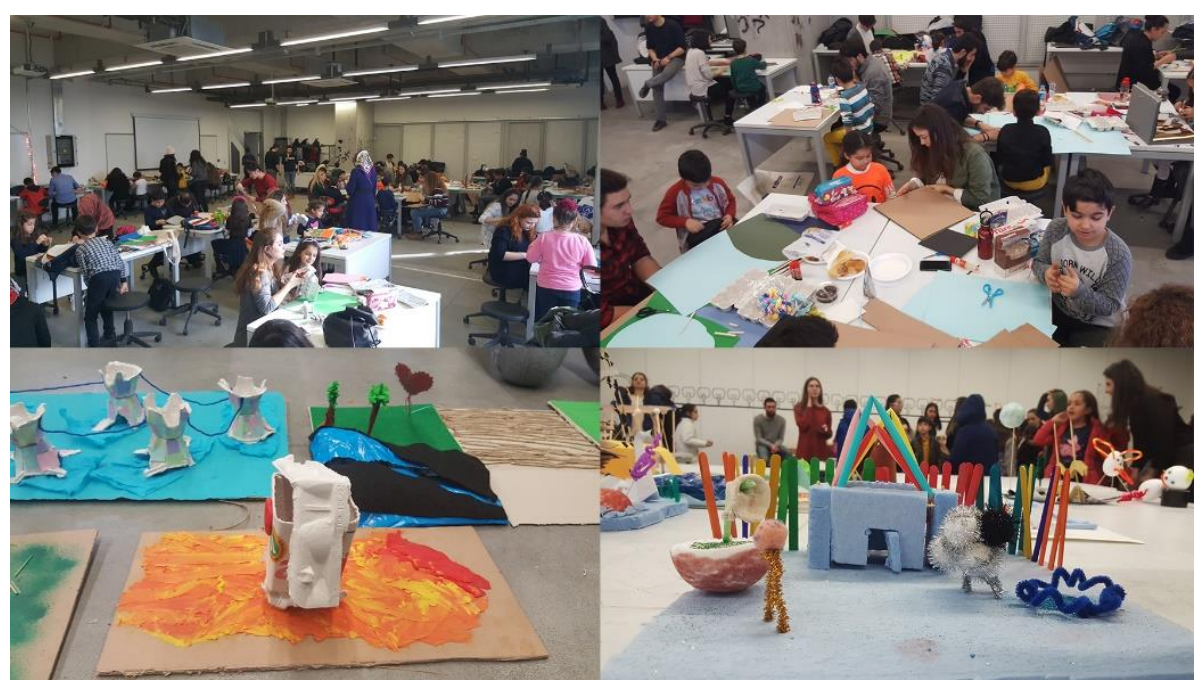

Şekil 7. Grup çalışmaları.

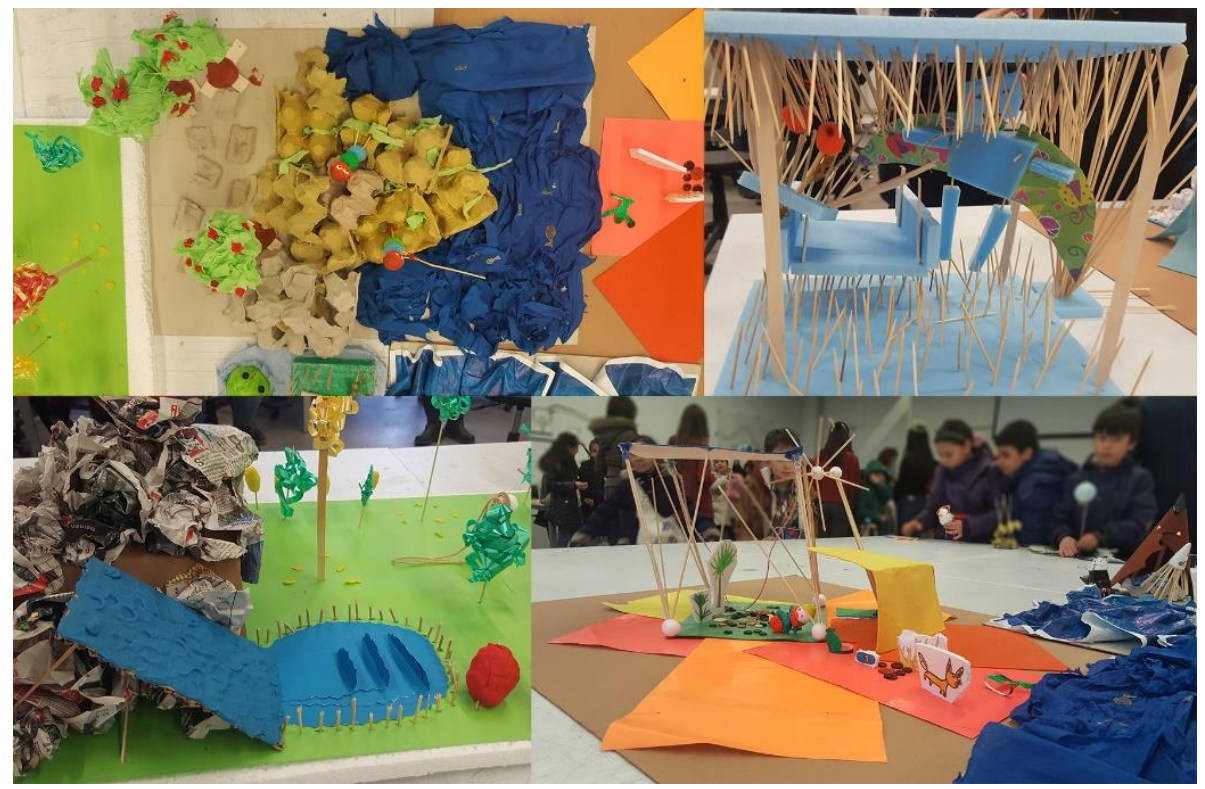

Şekil 8. Grup çalışmaları. 


\section{Değerlendirmeler}

Bir yıl arayla yapılan bu iki çalışmanın farklı yaş, cinsiyet ve eğitim durumuna göre bireyler üzerinde farklılaşma yarattığı görüldü. Özellikle ilköğretim öğrencilerinin tutum ve davranışlarında belirgin bir değişim olduğu, bu durumun psikolojik değerlendirme sonuçlarına da yansıdığ 1 gözlendi. Bu değişimde, ilköğretim öğrencilerinin sanat terapisti ve yaratıcı drama lideri olan bir öğretmenlerinin olması ve derslerinin ağırlıklı olarak bu çerçevede planlanmasının etkisini de vurgulamak gerekmektedir. Bu desteğe karşın ilk yıl kendi mahallelerinden çıkarak, başka bir okula üstelik bir üniversiteye gelen öğrencilerin duygudurumlarındaki değişim dikkat çekici olmuştur. Yapılan özdeğerlendirme ölçekleri incelendiğinde ilk sene çalışmaya katılan ilkokul öğrencilerinin durumluk kaygı düzeyinin yüksek olduğu belirlendi. Çalışma sırasında kendi okul yaşantılarında aşina olmalarına karşın, grup oluşturma, eşleşmeler ve yapılacak çalışmalar konusunda tedirgin olduklarını ifade eden sorular yöneltmişlerdir. İklim ve iklim değişikliği konusunda verilen bilgileri büyük bir dikkatle dinlerken sadece kendilerini kaygilandıracak bilgileri duydukları, iklim değişikliğini önleme konusunda ne yapmaları gerektiğine odaklanmak için kendilerini zorladıkları görülmüş̧ür. Bu, beklendik bir durumdur. Çünkü çocukların psikososyal gelişim evrelerinde "başarılı olmaya karşı yetersizlik duygusu'"'nu deneyimledikleri bir dönemde oldukları bilinmektedir (Miller, 2009, s. 150-156). Bu dönemde artık okul ve akademik başarı ön plana çıkmaktadır. Çocuk için öğrendikleriyle çevresinden beğeni ve takdir toplamak en temel ihtiyaç olmuştur. Çalışmaya katılan ilköğretim öğrencilerinin kendi bilgi, beceri ve donanımlarını sürece yansıtamamaları kaygılarını artırmıştır. Rahatlama ancak boyalar, makas, kağıtlar ve diğer malzemelerle karşılaşınca gerçekleşmiştir. Sonuç olarak, önceden planlamadan, içten geldiği gibi farklı cinsiyetten, yaşlardan, kültürlerden gelen, bilişsel gelişim özelliği olarak somut düşünen ve soyut düşünen bireylerin tanımlanmış bir sorun için çözüm üretebilmek adına çalışabilecekleri görüldü. Özellikle ilköğretim yaş grubu için, dikkatini uzun süreyle bir işe yönlendirmek, bir mekânda dört saat gibi uzun bir sure kalmak başarılması zor bir iştir.

Üniversite öğrencilerinin de kaygılı olduğu belirlendi. Bu yaş grubu "yakınlığa karşı yalıtılmışlık" sürecini yaşamaktaydı. Yoğun bir sınav maratonunu ile askıya aldıkları toplumsal meseleler üzerinde düşünme ve 
toplumun farklı katmanlarından bireylerle zaman geçirebilme becerilerindeki erozyonu fark ettikleri gözlemlendi. Hemen hepsinin benzer yaşlarda kardeşleri olmasına karşın "bir çocukla birlikte ortak hayal kurma ve bir düşünceyi tasarım yoluyla aktarma" fikrinden etkilendikleri görüldü. Planlı hareket etme ve tasarımın beğenilmesi kaygısını bırakıp çocukların sezgisel gücüyle hareket etmeye başladıklarında ortaya yaratıcı fikirler çıktığı gözlendi.

İkinci yıl ise ilkokul öğrencilerinin önceki yıldan deneyimli oldukları için daha rahat oldukları belirlendi. Ne yapacaklarını bildikleri için bu atölye çalışmasına ilk defa katılan üniversite öğrencilerini yönlendirdikleri görüldü. Grup dinamiğinin oluşmasında 1sınma oyunlarının ve eşlik eden öyküleşmiş anlatımların olumlu etkisi fark edildi. Oyunların sonunda grupların oluştuğu izlendi. Çalışmalar sırasında iki grup farklı yetişkin profili gözlendi. Kaygı düzeyi daha düşük olan mimarlık öğrencilerinin yaratım sürecini çocuğun yanında, onunla birlikte sürdürebildikleri; izin verici oldukları ancak kendi ihtiyaçlarından da vazgeçmedikleri görüldü. Bireyselliklerini koruyarak, grup sürecini yaşayabildikleri anlaşıldı. Bu gruplarda daha özgün ve sınırlarını aşmaya çalışan tasarımların ortaya çıtığı tespit edildi. Diğer profilde ise kontrol gücü yüksek yetişkinler olduğu görüldü. Bu profilde, çocuklarla birlikte yapılması gereken çalışmanın birden erişkinin görevi olarak ele alındığı gözlendi. Malzeme seçimi, yerleştirme gibi konularda doğrudan yönlendirme yapıldığı izlendi. Bu gruplar bir süre gözlendi ve çalışma süresince çalışmayı akışına bırakmaları konusunda, bildirimlerde bulunuldu. Bildirimler yanıt bulamadı. Ortaya çıkan ürünlerden iki katılımcının da hoşnut olmadığı belirlendi. Bu da iklim değişikliği gibi hayati bir meselede tüm tarafların katılımını sağlamadan üretilen çözümlerin neden kabul görmediğinin en açık örneği olarak belirginleşti.

\section{Sonuç}

Çalışmanın sonunda, yılda sekiz kez okul dışında eğitim ve gezi etkinliğine katılan ilköğretim öğrencilerinin, bu çalışmanın en sevdikleri olduğunu sözel olarak ifade ettikleri görülmüştür. İlköğretim öğrencileri, eğitim-öğretim dönemi sonu etkinlikleri kapsamında kendi yaşantılarına ait görsellerden oluşan bir sunuş hazırlamışlardır. Sene sonu gösterileri dâhil onlarca etkinliğin anlatıldığı sunuşta Mimarlık Bölümü ile yapılan atölye çalışması ekrana geldiğinde sınıfın hareketlendiği ve enerjilerinde fark 
edilir bir artış olduğu görülmüştür. Sınıf, TOBB ETÜ Mimarlık Bölümü ile yapılacak sonraki atölye çalışmasını desteklemek amacı ile “TEMA Çocuk" programına dâhil edildi. Kendi ortaklaşa kararları ile büyük bir çoğunluğu gönüllü TEMA üyeliği almışlardır. Bir yıllık tema eğitimlerini büyük bir ciddiyetle tamamlamışlardır. Bir sonraki sene Mimarlık öğrencileri ile ne çalışacakları konusunda oldukça meraklı ve istekli oldukları gözlenmiştir. TOBB ETÜ Mimarlık Bölümü 1. sınıf öğrencileri ise dönem sonu çalışması olarak iklim değişikliğinden etkilenecek yerler için yeni insan-doğa ekosistemleri öneren projeler hazırlamışlardır.

Değerlendirmeler sonucunda, atölyelerin tüm katılımcı ve yürütücüler için önemli bir deneyim, farkındalık, bilgi ve beceri kazanımı sağladığından hareketle, etkinliğin diğer ilköğretim okullarına yaygınlaştırılması için çalışma yapılması kararı alınmıştır. İklim değişikliğine dair farkındalık ve mücadele stratejilerinin TOBB ETÜ Mimarlık Bölümü Temel Tasarım Stüdyosu'nun sürekli bir bileşeni haline getirilmesine yönelik çalışmalara hız verilmiştir. Bu doğrultuda 2018-2019 Akademik yılı için planlanan atölyenin hedefinin Abdurrahim Karakoç İlkokulu bahçesi için sürdürülebilirlik, geri dönüşüm ve biyoçeşitlilik olması, öğrencilerin birlikte tasarladıkları çalışmaları birlikte üretmeleri ve kalıcı olarak okula bırakmaları öngörülmüştür.

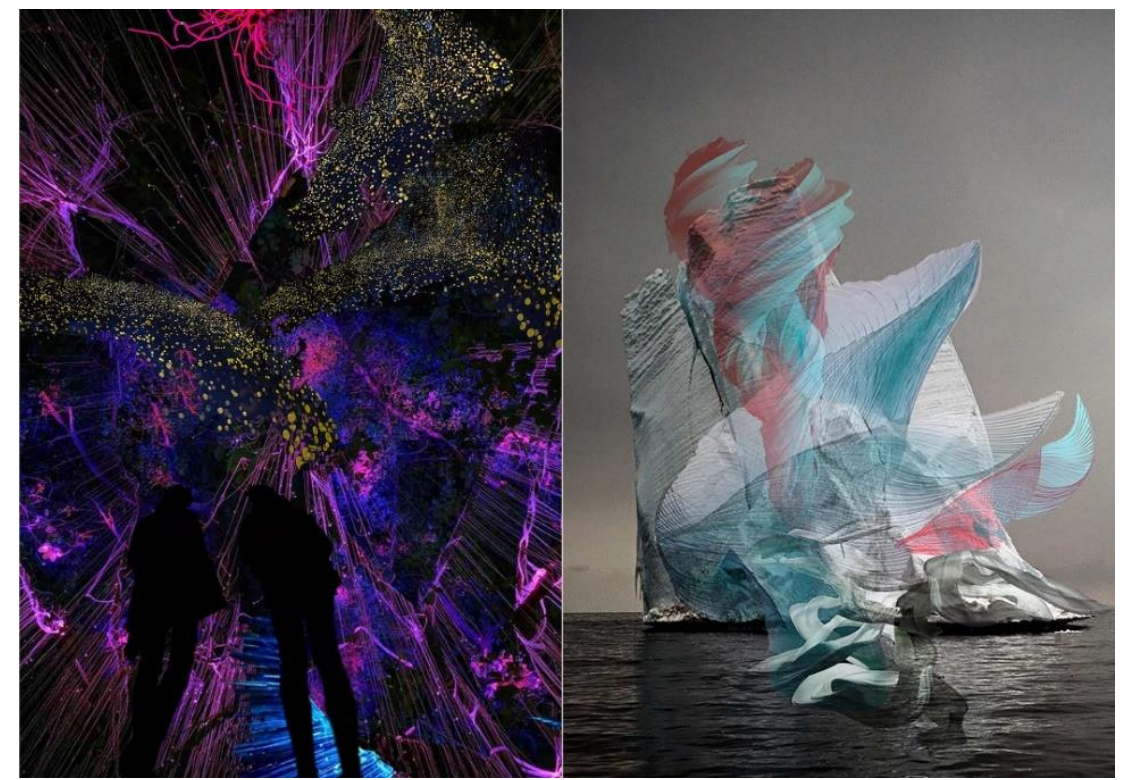

Şekil 9. Mimarlık Bölümü Temel Tasarım Stüdyosu Final Projeleri / Y. Alperen Pehlivan, Gökhan Sagun 


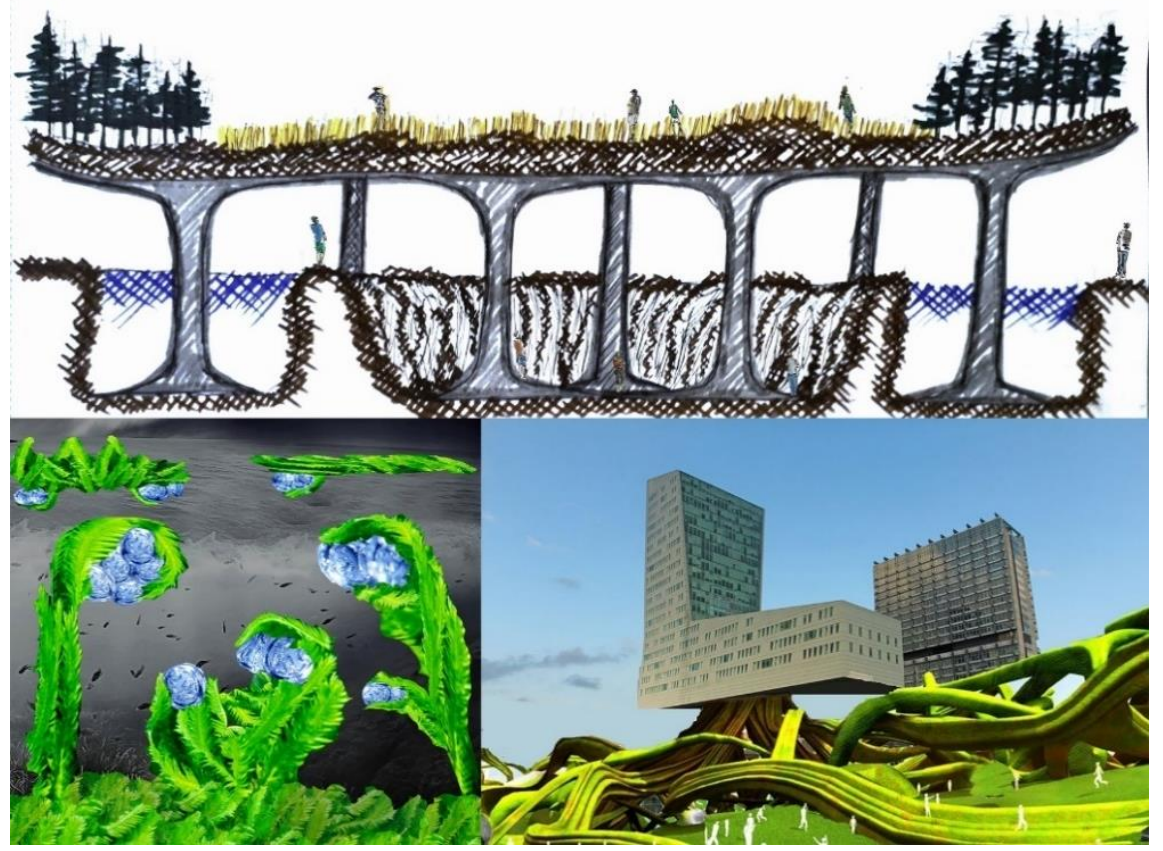

Şekil 10. Mimarlık Bölümü Temel Tasarım Stüdyosu Final Projeleri / Zeynep Akdemir, Büşra Bal, Emre Cansever 


\section{Extended Abstract}

\section{Design, Art and Game for a Resilient and Sustainable Future: Workshops for Children and Youth}

\author{
Aktan Acar \\ TOBB ETU \\ ORCID: 0000-0001-7243-3575
}

Nalan Akduman

Abdurrahim Karakoç Primary School

\author{
A. Şebnem Soysal Acar \\ Gazi University \\ ORCID: 0000-0002-6263-2340 \\ Yildiray Lise \\ The Nature Conservation Center
}

Climate system reflects the result of the complex interactions between the atmosphere, earth surfaces, snow and glaciers, oceans and the other water bodies, and every form of life. The most significant current threat for planet is the climate change. The human activity, as one of the most presumable sources of this threat is leading the world to accelerate on the improvements to raise environmental consciousness. Nowadays, the negative effects of climate change on human health is emphasized frequently. As the global threat of climate change is increasing, campaigns and activities to raise an awareness and initiate global and local action plans are having larger audience. Despite the increase in the accessible information on the negative effects of the climate change, there are limited researches focusing on the impacts of that massive information flow over the children and youth. It is of importance to notice that the awareness of children and youth is a key factor not only for the policy development and actions against climate change, but also for decreasing the destructive results and improving adaptation skills. This awareness and participation to the activities, however, can be a cause for anxiety for children and youth. In this respect, not only the awareness and adaptation oriented actions, education programs or trainings, but also the cognitive, emotional and behavioral impacts, changes, and consequences of those activities should be the utmost concern for the policy developers, activists, and especially educators. 
It is a fact that every member of our society has a responsibility and various ways of participation in struggle with climate change regarding to habitat, age, and profession. The interaction and collaboration of the various age groups, professions, and disciplines, therefore, seem the key of success in this sense. Particularly, the sensitivity and awareness of children and youth about the scope, methods and tools of various professions / disciplines would help them to improve their adaptation and collaboration skills in the future, with a lower anxiety level. This concern constitutes the main axis of the study we are presenting. The main objective of the study was to raise an awareness and decrease the anxiety level in two different age groups (freshmen in architecture and elementary school children) about climate change by means of design tasks and art techniques.

Primarily, the participants attended to the presentation on climate change, prepared by one biologist and one psychologist. After the presentations, in order both to have group cohesion and to raise an awareness on climate change, the art therapist took the stage. Participants played games nourished by the elements of creative drama. Following the warming up sessions, groups were formed and subjected to design tasks, which were blended by elements of art. In 2017, teams were asked to design a home for a biotic or abiotic survivor, as they would define, of climate change. They were given 2 hours to complete their work. In 2018, they were expected to develop a habitat for a group of a plant, an animal, an abiotic element and a human being. Group works ended up with exhibition and discussion session.

A difference in attitude and behaviors was observed in elementary school students. It was considered that collaborating with different age groups consecutively, alongside with their psycho-social development, affected the group dynamics positively. Two different types of attitude were identified in university students. Affirmative profile with low anxiety level was much more cooperative with children. Their synergy was concluded with creative solutions and positive feedbacks. On the other hand, dominant profiles considered the design process as tasks for adults. They attempted to take over the control in design and production. During design and modelling phase, they considered themselves as experienced designers, and endeavored to convince children about design ideas, proper materials, and preliminary decisions on forms. In that case, both parts reported negative feedbacks. It was considered that balanced and supportive participation is vital for creative and sustainable collaboration. 
Video recordings and students' own statements showed that elementary school children had wider perspectives for new ideas, but skeptic for predetermined forms and material uses proposed by the architecture students. It is observed that the art therapy techniques and games motivated the whole participants and affected the studio atmosphere in total. The anxiety level of both parties was decreased. But most importantly the knowledge they acquire about climate change influenced their point of view. They have noticed that design is not only an important tool to fight the impacts of climate change, but also powerful skill for adaptation. This awareness helped them to control their anxiety about the future.

Elementary school students were presented their works in their semester final exhibition. They reported that among many other activities held during the year, climate change workshops with university students were their favorite ones. They registered to "TEMA Çocuk" program. TOBB ETÜ $1^{\text {st }}$ year architecture students develop their semester final project on climate change issue and develop new human-nature ecosystem for the different parts of the planet impacted by the change.

It was decided to disseminate the results and workshop activity to other elementary schools in Ankara. Climate change oriented design problems have been integrated to the Basic Design Studio program at TOBB ETÜ Department of Architecture. For the 2018-2019 academic year, a design and build project for the school yard of the school was planned.

\section{Kaynakça/References}

Ahern, M., Kovats, R. S., Wilkinson, P., Few, R. ve Matthies, F. (2005). Global health impacts of floods: Epidemiologic evidence. Epidemiologic Reviews, 27, 36-46. doi:10.1093/epirev/mxi004

Beggs, P. J. ve Bambrick, H. J. (2005). Is the global rise of asthma an early impact on anthropogenic climate change? Environmental Health Perspectives, 113(8), 915919. doi:10.1289/ehp.7724

Checkley, W., Epstein, L. D., Gilman, R. H., Figueroa, D., Cama, R. I., Patz, J. A. ve Black, R. E. (2000). Effects of EI Niño and ambient temperature on hospital admissions for diarrhoeal diseases in Peruvian children. The Lancet, 335, 442450. doi:10.1016/S0140-6736(00)82010-3

Codreanu, T. A., Celenza, A. ve Jacobs, I. (2014). Does disaster education of teenagers translate into better survival knowledge, knowledge of skills, and adaptive behavioral change? A systematic literature review. Prehospital and Disaster Medicine, 29(6), 629-642. doi:10.1017/S1049023X14001083 
Datar, A., Liu, J., Linnemayr, S. ve Stecher, C. (2013). The impact of natural disasters on child health and investments in rural India. Social Science and Medicine, 76(1), 83-91. doi:10.1016/j.socscimed.2012.10.008

Kim, J. J. (2004). Ambient air pollution: health hazards to children. Pediatrics, 114(6), 699-707. doi:10.1542/peds.2004-2166

Midtbust, L. G. H., Dyregrov, A. ve Djup, H. W. (2018). Communicating with children and adolescents about the risk of natural disasters. European Journal of Psychotraumatology, 9(sup2), 1429771. doi:10.1080/20008198.2018.1429771

Miller, P. H. (2009). Theories of Developmental Psychology. New York: Worth Publishers.

Shea, K. M. (2007). Global Climate Change and Children's Health. Pediatrics, 120(5), e1359LP-e1367.

http://pediatrics.aappublications.org/content/120/5/e1359.abstract adresinden erişildi.

UNICEF. (2016). The State of the World's children 2016: A fair chance for every child. https://www.unicef.org/publications/files/UNICEF_SOWC_2016.pdf adresinden erişildi.

UNICEF. (2012). Climate Change adaptation and disaster risk reduction in the education sector resource manual. https://www.unicef.org/cfs/files/UNICEFClimateChange-ResourceManual-lores-c.pdf adresinden erişildi

Aktan Acar, 2000 yılında ODTÜ Mimarlık Bölümü'nden mezun oldu. 2003 yılında ODTÜ Mimarlık Anabilim Dalı'ndan, 2004 yılında İsviçre Federal Teknoloji Enstitüsü (ETH-Z) Mimarlık Bölümü' nden yüksek lisans derecesi aldı. 2006 yılında Ankara Üniversitesi Eğitim Psikolojisi doktora programına başladı. Mimarlık alanındaki doktora derecesini 2014 yılında Çankaya Üniversitesi Mimarlık Bölümü Tasarım Programı'ndan aldı. 2016 yılından bu yana TOBB ETÜ Mimarlık Bölümü öğretim üyesi.

B.Arch and M.Arch in Architecture from METU. M.Arch-Advanced Studies in Architecture from ETH-Z. PhD from Çankaya University, Faculty of Architecture. Currently works at TOBB University of Economics and Technology, Department of Architecture.

A. Şebnem Soysal Acar, Gazi Üniversitesi Tıp Fakültesi Çocuk Sağlığı ve Hastalıkları Ana Bilim Dalı öğretim üyesi. 1996 yılında Hacettepe Üniversitesi Psikoloji Bölümü'nden mezun oldu. Klinik Psikoloji yüksek lisansını 1999 yılında Hacettepe Üniversitesi'nde tamamladı. 2007 yılında aynı üniversitede, Deneysel Psikoloji alanında "doktor" unvanını almaya hak kazandı. 2012 yılında doçent oldu. 2013 yılında aile danışman1, 2016 yilında sanat terapisti oldu.

Bachelor's, Master in Clinical Psychology and PhD in Experimental Psychology, Hacettepe University. Dr. Soysal is an art threapist and family counsellor. She has been working as full time professor at Gazi University Faculty of Medicine Department of Pediatrics.

Nalan Akduman, Uludağ Üniversitesi Turizm ve Otelcilik bölümünden mezun olmuştur. 1997 yılında MEB’ de sınıf öğretmenliğine başlamıştır. 2011 yılında yaratıcı 
drama eğitmeni, 2016 yılında Sanat Terapisti olmuştur. 2009 yılından bu yana insan ve çocuk hakları, azınlıkların ve göçmenlerin uyumu konularında aktif olarak çalışmakta, Erasmus+ projelerinde proje koordinatörlüğü yapmaktadır. Üç yıldır TOBB Ekonomi ve Teknoloji Üniversitesi ve TEMA Vakfı ile iklim değişiklikleri, ekosistem ve sürdürülebilir yaşam konularında aktif çalışmalar ve projeler yürütmektedir.

Graduate of Toursim and Hotel Management program of Uludă̆ University. Since 1997, she has been working as a primary school teacher in public schools. She is an art therapist and creative drama leader and trainer. Running Erasmus+ projects and working on human and children rights, adaptation of minorities and immigrants.

Yıldıray Lise, ODTÜ Biyoloji Bölümü'nde lisans ve yüksek lisans eğitimini tamamladı. 2001 yılından itibaren sırasıyla Doğal Hayatı Koruma Derneği, Doğal Hayatı Koruma Vakfı ve Doğa Derneği gibi sivil toplum kuruluşlarında, Birleşmiş Milletler Kalkınma Programı (UNDP) Türkiye Ofisi ve özel sektörde uluslararası projeler yürüttü. 2014 yılından beri Doğa Koruma Merkezi Vakfı'nda Genel Müdür Yardımcısı olarak çalışıyor. Dünya Doğayı Koruma Birliği (IUCN) Korunan Alanlar Dünya Komisyonu üyesi olan Lise uzun yıllar UNESCO Türkiye Milli Komisyonu İnsan ve Biyosfer (MAB) İhtisas Komitesi üyeliği yaptı. Doğa koruma, sürdürülebilir kalkınma ve eğitim konularında uzun yıllardır çalışmalar yürütüyor. Dünyanın farklı dillerinde Küçük Prens kitapları koleksiyonu yapan ve resimli kitaplar okumayı seven Lise'nin bir kedisi bile yok.

B.Sc and M.Sc from the Middle East Technical University, Department of Biology. He is the Vice-director of the Nature Conservation Center, Ankara. Yildiray Lise is a member of International Union for Conservation of Nature Protected and Conserved Areas World Commission; and was a member of Turkish National Commission for UNESCO Man and the Biosphere Programme Committee. 